PESQUISA

\title{
AVALIAÇÃO MICROBIOLÓGICA DE SUSHIS COMERCIALIZADOS EM DOIS TIPOS DE RESTAURANTES DE POUSO ALEGRE - MG.
}

\section{MICROBIOLOGICAL EVALUATION OF SUSHI MARKETED IN TWO TYPES OF RESTAURANTS IN POUSO ALEGRE - MG.}

\author{
Breno Gomes da Silva ${ }^{1}$ \\ Universidade do Vale do Sapucaí, UNIVÁS. Pouso Alegre, MG, Brasil. \\ https://orcid.org/0000-0002-1704-3969 \\ breno_gomes_silva@hotmail.com \\ Gabriela Frazão Reimberg Silva² \\ Universidade do Vale do Sapucaí, UNIVÁS. Pouso Alegre, MG, Brasil. \\ https://orcid.org/0000-0003-4944-0982 \\ gabriela.alimentha@gmail.com \\ Luiz Francisley de Paiva ${ }^{3}$ \\ Universidade do Vale do Sapucaí, UNIVÁS. Pouso Alegre, MG, Brasil. \\ https://orcid.org/0000-0001-6497-7468 \\ francisleybiologo@yahoo.com.br
}

\begin{abstract}
${ }^{1}$ Conceptualização, metodologia, curadoria de dados, primeira redação, revisão e aprovação da versão final do trabalho.

${ }^{2}$ Administração do projeto, análise formal, conceptualização, metodologia, curadoria de dados, revisão e aprovação da versão final do trabalho.

${ }^{3}$ Administração do projeto, análise formal, conceptualização, metodologia, curadoria de dados, revisão e aprovação da versão final do trabalho.
\end{abstract}

\section{RESUMO}

O objetivo deste estudo foi avaliar os padrões microbiológicos de sushis preparados e comercializados em dois tipos de restaurantes no município de Pouso Alegre - MG. Foram adquiridas 32 amostras de sushis entre os meses de outubro a novembro de 2019 e realizadas pesquisa de coliformes totais, coliformes termotolerantes, Escherichia coli e estafilococos coagulase positiva. Para os testes de coliformes, as amostras foram inoculadas pela técnica pour plate utilizando o meio Agar Vermelho Violeta Bile. Para os testes de estafilococos coagulase positiva, foi utilizada a técnica de spread plate utilizando o meio Agar Baird Parker. Neste estudo não foram encontradas bactérias do grupo coliformes termotolerantes, entretanto, houve presença de coliformes totais em $59,37 \%$ das amostras. Em relação a estafilococos coagulase positiva, duas amostras foram positivas para este microrganismo, entretanto, apenas uma teve valores fora dos padrões estabelecidos pela legislação. Quando comparado os resultados entre os dois restaurantes, não houve diferença estatística entre eles. Neste estudo, com exceção de uma amostra, todas as outras amostras estão de acordo com os padrões de qualidade alimentar.

Palavras-chave: Alimentos preparados. Coliformes. Manipulação de alimentos. 


\section{ABSTRACT}

The objective of this study was to evaluate the microbiological patterns of sushi prepared and sold in 2 types of restaurants in the city of Pouso Alegre MG. Thirty-two samples of sushi were acquired between October and November 2019 and a search for total coliforms, thermotolerant coliforms, Escherichia coli and coagulase-positive staphylococci were carried out. For the coliform tests, the samples were inoculated by the pour plate technique using the Red Violet Bile Agar medium. For coagulase positive staphylococci tests, the spread plate technique using Baird Parker Agar medium was used. In this study, bacteria of the thermotolerant coliform group were not found, however, total coliforms were present in $59.37 \%$ of the samples. Regarding coagulase-positive staphylococci, two samples were positive for this microorganism, however, only one had values outside the standards established by legislation. When comparing the results between the two restaurants, there was no statistical difference between them. In this study, with the exception of one sample, all other samples meet food quality standards.

Keywords: Prepared Foods. Coliforms. Food Handling.

\section{INTRODUÇÃO}

No século XIX iniciou uma grande imigração oriental no Brasil, isso nos permitiu conhecer seus costumes, crenças, cultura e a culinária que embora tenha sofrido algumas adaptações devido à disponibilidade de ingredientes e aos hábitos da culinária brasileira, ainda assim, representam uma importante fatia no mercado de alimentação (SOARES; GAUDIOSO, 2014).

Com a importância que a alimentação oriental ganhou, ela já não é mais exclusividade dos restaurantes típicos, sendo facilmente encontrada nos mais diversos tipos de restaurantes e com novas formas de apresentação e variedade de ingredientes. (PROENÇA, 2010).

Um dos pratos orientais mais difundidos na alimentação dos brasileiros é o sushi. Ele é preparado a partir de uma combinação de: arroz japonês preparado com vinagre de arroz; pescado cru; alga nori; frutas; hortaliças e kanikama (TANAKA, 2003; MARÓCHIO et al., 2007).

O hábito de consumir pratos orientais caracterizados pela utilização de alimentos naturais, vegetais de modo geral e pescado cru, tem se tornando cada vez mais frequente, como uma boa alternativa para uma alimentação de forma mais saudável (PRADO et al., 2014; AMORIM, 2016).

O pescado apresenta excelente composição em aminoácidos, vitaminas e minerais e deste modo, é indispensável conservá-lo sob baixas temperaturas e sua manipulação deve ser realizada em condições de higiene uma vez que este alimento possui propriedades que o torna perecível e susceptível a deterioração (BRESSAN; PEREZ, 2000). 
A demanda aquecida motivou a indústria do pescado, sobretudo da aquicultura (cultivo de pescado), que é a modalidade com mais espaço para crescer. Em 2019 a produção brasileira de peixes de cultivo atingiu 758.006 toneladas. Esse desempenho representa crescimento de $4,9 \%$ sobre o ano anterior (722.560 toneladas). Entretanto, este grande desempenho ainda é insuficiente para atender a demanda brasileira. Ainda em 2019, o país importou 322.138 toneladas de pescado sendo que $30,11 \%$ deste total (96.992 toneladas) foram de Salmão (PEIXE BR, 2020).

Alguns fatores desde a obtenção da matéria-prima até o consumo do produto final podem favorecer o desenvolvimento de microrganismos e, consequentemente, doenças transmitidas por alimentos. Estabelecimentos produtores de alimentos precisam adotar medidas para garantir a qualidade higiênica sanitária e a conformidade dos alimentos com a legislação (SILVA; MATTÉ; MATTÉ, 2008).

As doenças transmitidas por alimentos são um grande problema de saúde pública, contabilizando custos econômicos e sociais. Foram criados requisitos higiênico-sanitários gerais para serviços de alimentação aplicáveis em todo território nacional, dispostos na RDC no 216 de 2004. Entre as medidas preventivas está a adoção de Boas Práticas de Fabricação, que são procedimentos que devem ser adotados por serviços de alimentação (BRASIL, 2004).

Desta maneira, o presente estudo teve como objetivo, avaliar os padrões microbiológicos de sushis preparados e comercializados em dois tipos de restaurantes no município de Pouso Alegre - MG, verificando se estes atendem aos padrões microbiológicos estabelecidos pela RDC № 331 (BRASIL 2019a).

\section{METODOLOGIA}

Foram adquiridas 32 amostras de sushis preparados e comercializados em dois tipos de restaurantes: um especializado em cozinha oriental e o outro comum. As amostras foram adquiridas durante os meses de outubro a novembro de 2019 no município de Pouso Alegre - MG. As amostras adquiridas foram embaladas no próprio estabelecimento e transportadas para o Laboratório de Pesquisas Básicas em uma caixa isotérmica contendo gelo. A realização dos testes não excedeu 24 horas após a aquisição.

As amostras foram analisadas para verificação quantitativa de bactérias dos grupos coliformes totais e termotolerantes e também para Estafilococos coagulase positiva seguindo os protocolos da American Public Health Association descrita no Compendium of methods for 
the microbiological examination of foods (APHA, 2015).

\section{Preparo das amostras}

Inicialmente, $25 \mathrm{~g}$ das amostras foram transferidas para um erlenmeyer contendo $225 \mathrm{~mL}$ de peptonada $\left(\mathrm{H}_{2} \mathrm{O}_{\mathrm{p}}\right)$ $0,1 \%$. As amostras foram diluídas homogeneizando 0 frasco durante 5 minutos. A partir desta solução, realizouse diluições seriadas decimais de 1:10, $1: 100$ e $1: 1000(v / v)$.

\section{Pesquisa de coliformes totais e termotolerantes}

Após homogeneização, $1 \mathrm{~mL}$ de cada diluição foram dispensadas no centro das respectivas placas de Petri estéril $100 \mathrm{~mm}$. Em seguida foi adicionado em cada placa o meio Agar Vermelho Violeta Bile previamente fundido. As placas foram fechadas imediatamente e foram homogeneizados com movimentos de "8". Após a solidificação do meio, foi adicionada novamente sobre as mesmas placas, uma sobrecamada de aproximadamente 5 - $8 \mathrm{~mL}$ do meio Agar Vermelho Violeta Bile. As placas foram identificadas e incubadas a $24-48$ horas a $35^{\circ} \mathrm{C} \pm 2^{\circ} \mathrm{C}$. Após esse período, as colônias típicas e também atípicas quando presentes, foram contadas e após, foram determinados o número de UFC/g.

Para a confirmação de coliformes totais, colônias típicas e atípicas de cada placa foram inoculadas em tubos contendo $9 \mathrm{~mL}$ de meio Caldo Verde Brilhante Bile 2\% Lactose contendo tubo de Durhan invertido. Os tubos foram incubados por $24-48$ horas a $35^{\circ} \mathrm{C} \pm 2^{\circ} \mathrm{C}$ e após esse período foi verificada a presença de turbidez do meio com formação de gás sendo este o resultado positivo confirmativo para coliformes totais.

A verificação da presença de coliformes termotolerantes foi realizada através da repicagem dos tubos positivos de Caldo Verde Brilhante Bile 2\% Lactose para tubos com o meio Caldo Escherichia coli, contendo tubo de Durhan invertido. Depois de homogeneizados, os tubos foram incubados em banho-maria a $45^{\circ} \mathrm{C}$ durante 24 horas. A turvação e formação de gás nos tubos de Durhan confirma a presença de coliformes de origem fecal.

\section{Pesquisa de Estafilococos coagulase positiva}

Para as análises de Estafilococos coagulase positiva, foram inoculados 100 $\mu \mathrm{L}$ de cada diluição em placas contendo o meio Agar Baird Parker suplementado com emulsão gema de ovo e telurito de potássio $1 \%$. O inóculo foi espalhado sobre a superfície do meio com auxilio de uma alça de drigalski. As placas foram identificadas e incubadas a 24-48 horas a $35^{\circ} \mathrm{C} \pm 2^{\circ} \mathrm{C}$. Após esse período, as colônias típicas e também atípicas quando presentes, foram contadas e após, foram determinados o número de UFC/g. 
Para a confirmação, foram selecionadas cinco colônias de cada placa e transferidas para tubos contendo Caldo Infusão Cérebro Coração. Os tubos foram incubados a $35^{\circ} \mathrm{C} \pm 2^{\circ} \mathrm{C}$ por $18-24$ horas. Após esse período $0,2 \mathrm{~mL}$ da cultura foram transferidos para tubos contendo $0,5 \mathrm{~mL}$ de plasma de coelho com EDTA e incubados por 6 horas a $35^{\circ} \mathrm{C} \pm 2^{\circ} \mathrm{C}$ com verificação periódica. Ao final desse período, foi avaliada a formação de coágulos quando presentes e atribuídos uma nota de nível que varia de 1+ à 4+, sendo considerado confirmativo para Estafilococos coagulase positiva os níveis $3+$ e $4+$.
A diferença da qualidade microbiológica entre os estabelecimentos estudados foi avaliada por meio das médias de crescimento microbiano obtidas nas avaliações de cada teste microbiológico comparadas pelo teste de Tukey, a 5\% de probabilidade $(P<0,05)$ utilizando-se o Software R 2.5.1 (2007).

\section{RESULTADOS E DISCUSSÃO}

Os resultados das análises microbiológicas estão demonstrados nas Tabelas 1 (restaurante especializado em comida oriental) e 2 (restaurante comum).

Tabela 1 - Qualidade microbiológica de sushis comercializado em restaurante especializado em comida oriental.

\begin{tabular}{|c|c|c|c|c|c|c|}
\hline \multirow{2}{*}{ Data } & \multirow{2}{*}{ Amostra } & \multicolumn{2}{|c|}{ Estafilococos } & \multicolumn{3}{|c|}{ Coliformes } \\
\hline & & UFC/g & Coagulase positiva & UFC/g & Total & Termotolerante \\
\hline \multirow{4}{*}{ 27/out } & 1 & 0 & - & 680 & - & - \\
\hline & 2 & 100 & - & 280 & - & - \\
\hline & 3 & 3000 & - & 400 & - & - \\
\hline & 4 & 200 & - & 650 & - & - \\
\hline \multirow{4}{*}{ 03/nov } & 5 & 2700 & - & 0 & - & - \\
\hline & 6 & 100 & - & 620 & + & - \\
\hline & 7 & 1700 & - & 660 & + & - \\
\hline & 8 & 300 & - & 50 & + & - \\
\hline \multirow{4}{*}{$10 /$ nov } & 9 & 1800 & - & 10 & + & - \\
\hline & 10 & 100 & - & 70 & + & - \\
\hline & 11 & 1200 & - & 40 & + & - \\
\hline & 12 & 1000 & - & 70 & + & - \\
\hline \multirow{4}{*}{$17 /$ nov } & 13 & 400 & - & 0 & - & - \\
\hline & 14 & 0 & - & 10 & + & - \\
\hline & 15 & 4900 & - & 30 & + & - \\
\hline & 16 & 1500 & - & 10 & + & - \\
\hline
\end{tabular}

UFC/g: unidade formadora de colônia por grama; (+) positivo; (-) negativo. 


\begin{tabular}{|c|c|c|c|c|c|c|}
\hline \multirow{2}{*}{ Data } & \multirow{2}{*}{ Amostra } & \multicolumn{2}{|r|}{ Estafilococos } & \multicolumn{3}{|c|}{ Coliformes } \\
\hline & & UFC/g & Coagulase positiva & UFC/g & Total & Termotolerante \\
\hline \multirow{4}{*}{ 27/out } & 17 & 3700 & - & 3700 & + & - \\
\hline & 18 & 1500 & - & 300 & + & - \\
\hline & 19 & 1900 & - & 500 & + & - \\
\hline & 20 & 1700 & - & 4400 & + & - \\
\hline \multirow{4}{*}{ 03/nov } & 21 & 700 & - & 0 & - & - \\
\hline & 22 & 300 & + & 0 & - & - \\
\hline & 23 & 1300 & + & 14000 & + & - \\
\hline & 24 & 600 & - & 2000 & + & - \\
\hline \multirow{4}{*}{$10 /$ nov } & 25 & 1300 & - & 0 & - & - \\
\hline & 26 & 900 & - & 40 & + & - \\
\hline & 27 & 800 & - & 0 & - & - \\
\hline & 28 & 700 & - & 0 & - & - \\
\hline \multirow{4}{*}{ 17/nov } & 29 & 1800 & - & 0 & - & - \\
\hline & 30 & 1500 & - & 0 & - & - \\
\hline & 31 & 1000 & - & 60 & + & - \\
\hline & 32 & 1800 & - & 0 & + & - \\
\hline
\end{tabular}

UFC/g: unidade formadora de colônia por grama; (+) positivo; (-) negativo.

De um total de 32 amostras de sushis analisadas, em 96,75\%, foram encontradas crescimento de cepas do gênero Staphylococcus sp., entretanto, em apenas duas amostras, coletadas no mesmo dia no restaurante comum (Tabela 2), houve a presença de Estafilococos coagulase positiva, sendo que apenas uma obteve valores fora do limite estabelecido na Instrução Normativa $n^{\circ} 60$ que é de $10^{3} \mathrm{UFC} / \mathrm{g}$ (BRASIL, 2019b).

A maioria de estafilococos encontrados eram coagulase negativa que, embora não seja um patógeno em potencial e nem microrganismo de estudo, sua presença chama a atenção quanto às práticas de preparo e o acondicionamento do prato até o momento do consumo.
Para pesquisa de bactérias do grupo coliformes, neste estudo não foram encontrados crescimento de coliformes termotolerantes satisfazendo assim os critérios da resolução vigente, no entanto, em $59,37 \%$ das amostras houve presença de coliformes totais e, mesmo que sua contagem não é exigida por essa resolução, sua presença sugere uma falha no processo de preparo e de deficiência na qualidade higiênico sanitária do alimento já que estes microrganismos são contaminantes ambientais (BRANT; FONSECA; SILVA, 2012).

Quando comparada a qualidade microbiológica do sushi entre os restaurantes especializado e não especializado, não houve diferença estatística entre eles com valor de $p=$ 
0,114 para coliformes totais (Figura 1) e 0,698 para Staphylococcus sp. (Figura 2).

Figura 1 - Presença de bactérias do grupo coliformes totais nos restaurantes comum e especializado.

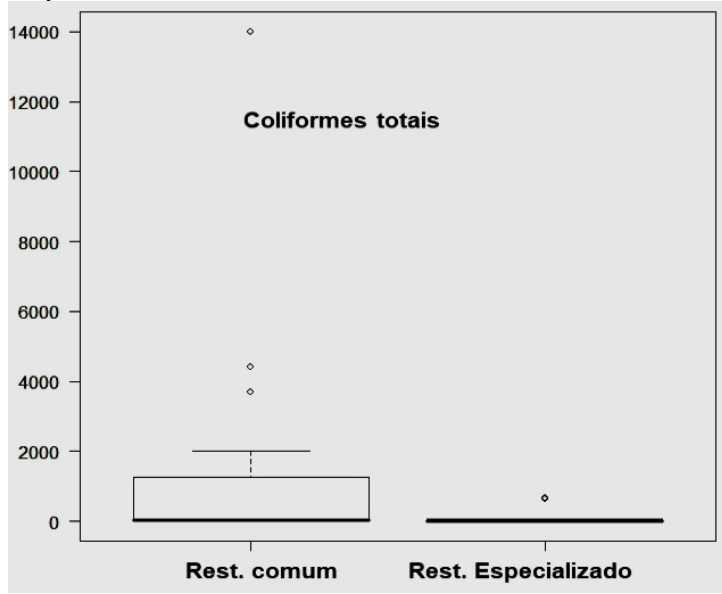

Figura 2 - Presença de Staphylococcus sp. nos restaurantes comum e especializado.

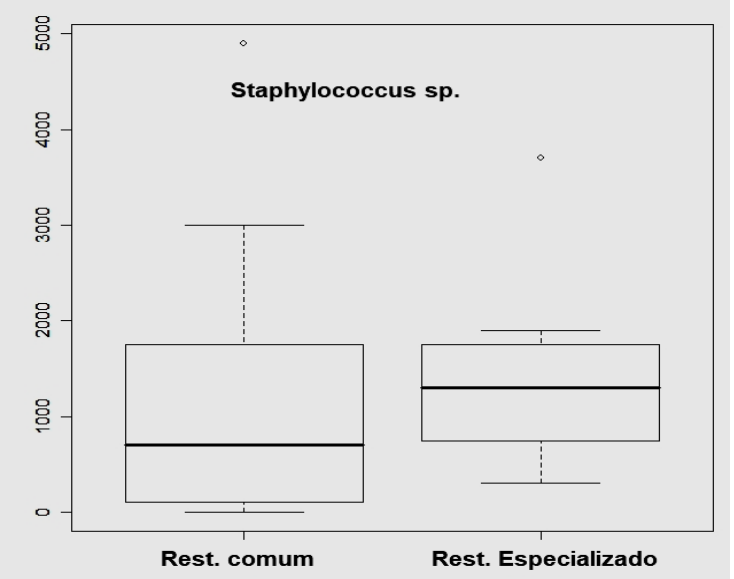

A presença de estafilococos coagulase negativa e de coliformes totais nas amostras sugere falhas no processo de manipulação dos alimentos, limpeza e sanitização já que os microrganismos em questão estão associados a manipuladores e de contaminação ambiental respectivamente. No estudo de Moraes, Darley e Timm (2019), a análise de Estafilococos coagulase positiva resultou em contagens superiores ao limite estabelecido pela ANVISA em três amostras (15\%).

No estudo de Santos e colaboradores (2012), em restaurantes que comercializam sushi em Aracaju - SE, foram encontradas, em 20 amostras das 35 analisadas, bactérias do gênero Staphylococcus sp., sendo que 16 delas foram identificadas como $S$. aureus e dessas, quatro apresentaram contagem acima do que é estabelecido pela legislação.

Bactérias do grupo coliformes totais são encontradas no trato intestinal de animais e seres humanos e pertencem à família Enterobacteriaceae (TRABULSI; ALTERTHUM, 2008). A presença deste microrganismo no alimento indica que houve algum erro nas condições de higiene durante a preparação (FORSYTHE, 2013).

Pinheiro e colaboradores (2006), ao analisarem 30 amostras provenientes de cinco estabelecimentos que comercializavam sushi e sashimi na cidade de Fortaleza - CE, encontraram em nove amostras valores médios para coliformes termotolerantes, entretanto, em uma amostra houve valores acima do estabelecido pela legislação para coliformes termotolerantes, assim sendo imprópria para o consumo.

Resende, Souza e Oliveira (2009), ao analisarem amostras de sushis e 
sashimis na cidade de Brasília - DF observou que $25 \%$ das amostras apresentaram valores para coliformes termotolerantes acima do permitido.

No estudo de Santos e colaboradores (2012), em restaurantes que comercializam sushi em Aracaju - SE, foram encontradas 28 amostras de 35 analisadas, níveis acima do limite para coliformes totais e termotolerantes além da presença das bactérias Staphylococcus aureus e Salmonella sp.

Madrigal e colaboradores (2013), analisaram 60 amostras a partir de 13 estabelecimentos em pontos distintos na cidade de San José em Costa Rica. Os autores verificaram que dentre os 13 estabelecimentos, seis apresentaram amostras com a presença de E. coli e sete para S. aureus, sendo impróprios para consumo.

No presente estudo, com exceção de uma amostra, todas as outras amostras avaliadas pelos métodos microbiológicos estão de acordo com a Instrução Normativa no 60 que complementa a resolução da RDC n 331 .

Os resultados indicam a necessidade de maior atenção às medidas higiênicas e sanitárias adotadas durante o armazenamento, preparo e especialmente a manipulação do produto. Segundo Moraes, Darley e Timm (2019), por se tratar de um alimento consumido in natura, há um risco aumentado de contaminação devido à manipulação humana. Oliveira e colaboradores (2003), concluíram que as condições higiênicosanitárias do ambiente, qualidade da água, bem com a maneira de manipulação, influenciam diretamente na qualidade microbiológica do alimento.

A necessidade de maior atenção na área de segurança alimentar é evidente. Melhorias nos métodos de processamento dos alimentos e a conscientização a respeito de segurança alimentar de todos os envolvidos na cadeia de produção de alimentos reduziria a incidência das doenças de origem alimentar (DTA's). Muitas práticas inadequadas que ocorrem durante 0 processamento, permitem as contaminações, pela sobrevivência e pela multiplicação de microrganismos patogênicos nos alimentos.

$$
\text { Segundo Vallandro e }
$$
colaboradores (2011), práticas higiênicas eficientes são necessárias em cada passo da cadeia alimentar, desde a produção até o consumo dos alimentos no qual cada etapa pode influenciar a qualidade e a segurança dos alimentos. $O$ autor ainda ressalva que tais práticas devem ser controladas pela adoção de Boas Práticas de Fabricação e monitoradas pelas autoridades sanitárias.

A implantação de programas de Boas Práticas de Fabricação (BPF) poderá promover a segurança alimentar aos consumidores no controle das DTA's. 
Essa pesquisa contribuiu de forma positiva para a população a partir das análises microbiológicas, tendo em vista que o produto quando fora dos padrões pode levar a complicações mais severas, constituindo de um sério problema de saúde pública e que, portanto, deve ser melhor fiscalizado e tratado antes de ser consumido.

\section{CONCLUSÃO}

Apenas uma das amostras avaliadas pelos métodos microbiológicos está fora dos padrões estabelecidos na Instrução Normativa no 60 complementar a RDC $n^{\circ}$ 331. Não houve diferença estatística entre os restaurantes quanto à qualidade microbiológica do sushi. A presença de Estafilococos coagulase negativa $e$ de coliformes totais nas amostras sugere falhas no processo de manipulação dos alimentos, limpeza e sanitização já que os microrganismos em questão estão associados a manipuladores e de contaminação ambiental respectivamente.

\section{REFERÊNCIAS BIBLIOGRÁFICAS}

AMERICAN PUBLIC HEALTH
ASSOCIATION (APHA). Committe on
Microbiologycal Methods for Foods.
Compendiun of Methods for the
Microbiologycal Examination of Foods.
Washington: APHA, 2015.

AMORIM, M.S.M.A. O imigrante chinês no Brasil e no Sudeste: Uma análise dos dados do Censo demográfico (2010) e SINCRE - Polícia Federal (2000 a 2014). Caderno de Geografia, v. 26, n. 1, 2016.

BRANT, L. M. F.; FONSECA, L. M.; SILVA, M. C. C. Avaliação da qualidade microbiológica do queijo-de-minas artesanal do Serro-MG. Revista Brasileira de Produtos Agroindustriais, Campina Grande, v.14, n.2, p.125-130, 2012.

BRASIL, Ministério da Saúde. Agência Nacional de Vigilância Sanitária. Resolução - RDC № 216, de 15 de setembro de 2004. Dispõe sobre regulamento técnico de boas práticas para serviços de alimentação. Diário Oficial da União. Brasília, DF, 2004.

BRASIL. Ministério da Saúde. Agência Nacional de Vigilância Sanitária. Resolução - RDC № 331, de 23 de dezembro de 2019. Dispõe sobre o regulamento técnico sobre padrões microbiológicos para alimentos. Diário Oficial da União. Publicado em: 26/12/2019. Edição: 249, Seção: 1, Página: 96. Brasília, DF, 26 de dezembro de 2019a.

BRASIL. Ministério da Saúde. Agência Nacional de Vigilância Sanitária. Instrução Normativa $\mathrm{N}^{\circ} 60$, de 23 de dezembro de 2019. Estabelece as listas de padrões microbiológicos para alimentos. Diário Oficial da União. Publicado em: 26/12/2019. Edição: 249, Seção: 1, Página: 133. Brasília, DF, 26 de dezembro de 2019b.

BRESSAN, M. C.; PEREZ, J. R. O. Tecnologia de carnes e pescados. Lavras: UFLA/FAEPE; 2000. 225 p.

FORSYTHE, S. J. Microbiologia da segurança dos alimentos. 2 ed, Porto Alegre: Artmed,2013.

MADRIGAL, A. P.; LÓPEZ, C.; ARIAS, M. L.; SALAS, P.; CHAVES, C. Estudo bacteriológico de sushi preparado y 
comercializado en San José, Costa Rica. Revista Costarr Salud Pública. v.22, n.01. Costa Rica, 2013.

MARÓCHIO, A.; SOARES, C. M.; TAKARA, E. M.; OLIVEIRA, M. C.; PAVON, R. R. D. A influência da culinária chinesa em São Paulo. UAM, São Paulo, 2007. 63p. (Monografia de especialização) - Universidade Anhembi Morumbi, SP, 2007.

MORAES, T. P.; DARLEY, F. M.; TIMM, C. D. Avaliação microbiológica de sushi e sashimis preparados em restaurantes especializados. Revista de Ciências Agroveterinárias, v.18, n.2, p. 254-257, 2019.

OLIVEIRA, A. M. GONÇALVES, M. O.; SHINOHARA, N. K. S.; STAMFORD, T. L. $M$. Manipuladores de alimentos: um fator de risco. Higiene Alimentar, Recife, v. 17, n. $114 / 115$, p. $12-19,2003$.

PEIXE BR. Associação brasileira de piscicultura. Produção cresce 4,9\% e atinge em 2019 758.006 T. Anuário Peixe BR da piscicultura 2020. Disponível em: https://www.peixebr.com.br/anuario-2021/.

PINHEIRO, H. M. C.; VIEIRA, R. H. S. F.; CARVALHO, F. C. T.; REIS, E. M. F.; SOUSA, O. V.; VIEIRA, G. H. F.; RODRIGUES, D. P. Salmonella sp. e coliformes termotolerantes em sushi e sashimi comercializados na cidade de Fortaleza-Ceará. Boletim Técnico Científico do Cepene, v. 14, n. 1, p. 2331, 2006.

PRADO, B. G.; IWATANI, J. E.; PEREIRA, M. R.; GOLLUCKE, A. P. B.; TOLEDO, L. $P$. Pontos críticos de controle na qualidade higiênico-sanitária do preparo de sushis e sashimis no município de São Vicente, São Paulo. Segurança Alimentar e Nutricional, Campinas, v. 21, n. 1, p.359- 372, 2014.

PROENÇA R. P. C. Alimentação e globalização: algumas reflexões. Ciência Cult. n.62, p.43-47, 2010.
RESENDE, A.; SOUZA, J. R.; OLIVEIRA, Y. S. Análise microbiológica de sushis e sashimis comercializados em restaurantes de Brasília no período de 2001 a 2004. Revista Higiene Alimentar, v. 23, $\mathrm{n}$. 174/175, p. 164-70, 2009.

SANTOS, A. A.; SIMÕES, G. T. N.; CRUZ, M. M.; FERREIRA, N. S. S.; LIMA, R. T. C.; TUNON, G. I. L. Avaliação da qualidade microbiológica de sushi comercializado em restaurantes de Aracaju, Sergipe. Scientia Plena. v. 08, n. 03. 2012.

SILVA, M. L.; MATTÉ, G. R.; MATTÉ, M. $H$. Aspectos sanitários da comercialização de pescado em feiras livres da cidade de São Paulo, SP/Brasil. Revista do Instituto Adolfo Lutz, São Paulo, v.67, n.3, p.208-214, 2008.

SOARES, A. L. R.; GAUDIOSO, T. K. As imigrantes japonesas no Rio Grande do Sul: Suas funções na preservação da cultura do país de origem. In: $12^{\mathrm{a}}$ Semana de Museus. Universidade Federal do Rio Grande do Sul, 2014.

TANAKA, A. M. D. M. Imigração e colonização japonesa no Brasil. Revista da Faculdade de Direito da Universidade Federal do Rio Grande do Sul, Porto Alegre, p.37 - 41, 2003.

TRABULSI, L. R.; ALTERTHUM, F. Microbiologia. 5 ed. São Paulo: Atheneu, p. 21-28, 2008.

VALLANDRO, M. J.; CAMPOS, T.; PAIM, D.; CARDOSO, M.; KINDLEIN, L. Avaliação da qualidade microbiológica de sashimis à base de salmão, preparados em restaurantes especializados em culinária japonesa. Revista do Instituto Adolfo Lutz, v.70, n.144-150, 2011. 